\title{
The marginalisation of religion in End of Life Care: signs of microaggression?
}

\author{
Dr. Panagiotis Pentaris ${ }^{a, b}$ \\ ${ }^{a}$ Department of Psychology, Social Work and Counselling | University of Greenwich \\ ${ }^{\mathrm{b}}$ Faiths and Civil Society Unit | Goldsmiths, University of London
}

\section{Acknowledgements}

I would like to thank all practitioners and patients who willingly decided to participate in this study. Without their contribution, this project would not have concluded.

\section{Declaration}

This paper has not been published before or submitted to another publisher for consideration. 


\title{
The marginalisation of religion in End of Life Care: signs of microaggression?
}

\begin{abstract}
Service users very often interpret and respond to their experiences of death, dying and bereavement through a religious or spiritual lens. However, recent trends in religion and belief have influenced how professionals respond to indicators such as faith. Since the post-war years in Britain, and due to the transfer of services from church to state, as well as the change in the religious landscape, language has largely secularized. When people start addressing religion and belief again, they lack the appropriate literacy to do so; this is termed religious literacy by Dinham (2015). This paper explores how professionals in end of life care respond to service users' religious and spiritual indicators, through the lens of religious literacy. The paper draws from an ethnographic study undertaken across hospices in England, UK. In this study healthcare professionals were observed for one calendar year. Results show that lack of religious literacy on the part of healthcare professionals may lead to subtle and unintentional microaggression. Three types of indications of microinvalidation have been noted: verbal, nonverbal and environmental.
\end{abstract}

Keywords: religion, religious microaggression, religious microinvalidation, end of life care, hospice

\section{Introduction}

Religion, belief and spirituality are conceptual informants of how individuals experience death, dying and bereavement (Malinowski, 1954/2015; Becker, 1963; Kaufman, 1976). Example areas that illustrate this include the afterlife (Scheffler and Kolodny, 2013; Kaufman, 1976), coping with suffering (Wong, 2008), life review (Ardelt, 2003), ethical treatment decisions, to 
name a few. Sacred teachings set out the after-death experience: what follows, when and how. Such explanations or descriptions of one's experience minimize anxiety for the unknown (Kim, 2008). In other words, religion, belief and spirituality answer the critical question 'what happens after I die?'

In response to that, as well as considering holistic and person-centered care, spiritual care has largely developed in end of life (EOL) care over the last fifty years, ever since the hospice movement. Cicely Saunders, a well-educated Christian nurse, social worker and physician suggested that the care of the dying patient should be holistic; it should cover all areas of care, including physical, psycho-social and spiritual (Saunders, 2005). Unlike Saunders, this paper considers spiritual care a sub-category, which normally finds place under the psycho-social care of the service user and this feeds into the present argument.

Despite the precision of spiritual care, the intentions, as well the purpose that it serves, there were two stories written concurrently. One was about EOL care and the emergence of spiritual care as briefly mentioned above. The other was written by policy and politics, and it was concerned with equality and equity (e.g., Equality Act 2010), social inclusion, human rights (e.g., Human Rights Act 1998) and service provision generally (also see EU Equal Treatment Directives). Even though the state was the core commissioner of welfare services, including healthcare, in the post war years, the church remained in its role as a service provider, but in a subtle form (Dinham, 2015), whether that was in the form of philanthropy, volunteerism or other forms.

The division of service delivery between providers resulted in the psychosocial models giving way to the bio-medical (Author's own, 2015). Approaches in end of life care became largely medicalized (Walter, 1999; 1994). Grief and bereavement are now often seen as institutionalized conditions, rather than natural expressions (Kellehear, 2017; Hart, Sainsbury and Short, 1998). Starting with the well renowned 5 stages model by Kübler-Ross (1969), the 
emergence of all different models of grief might as well be considered an unintentional or intentional attempt to pathologise grief; to classify what otherwise cannot be measured, monitored, or on some occasions, even controlled. However, studies lean towards both sides; the institutionalization of grief either supports or jeopardizes the service user experience (Walter, 1999; Goldsworthy, 2005). Regardless, the dominance of bio-medical approaches enhanced the increase in the use of secular language (Author's own, 2015).

Having said that, contemporary professional practice in EOL care appears to have developed within a secular-minded environment, one that did not recognize religion and belief as visible enough identities in order to address them properly (Dinham and Francis, 2015). Spirituality has often been used as a proxy to address religion and belief. Therefore, health care professionals (HCPs) became accustomed to talk about spirituality, meaning making and meditation (Kuczewski, 2007). Simultaneously, they have lost ability to talk about religion and belief, and were challenged once religion became a subject of public talk again (Author's own, 2015).

This paper aims to introduce a discussion around the implications of a lack of religious literacy, through the lens of microaggression. To do so it explores the terms religious literacy and microaggression, in order to specify how they are being used here. The paper illustrates the findings by the use of vignettes, ones having emerged from participant observation in hospice care and it explores the findings with cultural humility in mind (i.e., tendency of respect and lack of superiority toward the other) (Hook et al., 2013). The paper is inclusive of conclusions and discussion, while it considers implications for research and practice, with a particular focus on social work.

\section{Religion and human rights}


The relationship between religion and human rights is dual. On the one hand, religion as wisdom and a set of values is crucial in the battle for human rights. Witte $(1998 ; 2)$ best puts this:

For human rights laws are inherently abstract ideals - universal statements of the good life and the good society. They depend upon the visions of human communities and institutions to give them content and coherence, to provide "the scale of values governing the(ir) exercise and concrete manifestation." Religion is an ineradicable condition of human lives and communities. Religions invariably provide universal sources and "scales of values" by which many persons and communities govern themselves. Religions must thus be seen as indispensable allies in the modern struggle for human rights.

Equally important, human rights laws have a responsibility to safeguard people's rights to religion, faith and the expression of their beliefs (Taylor, 2005). From the adoption of the United Nations Charter in 1945 and the Universal Declaration of Human Rights in 1948, to the Human Rights Act 1998 and the Equality Act 2010 in the UK, human rights laws have done two things (Freeman, 2017). First, legitimize and validate the importance of safeguarding people's rights, in this instance, to belief, faith, religion, religious affiliation and the way they express any of those. Second, human rights laws provide assurance to the public and inform the principles that institutions ought to adhere to.

The Universal Declaration of Human Rights (1948) specifically states (Article 2) that all individuals are entitled to their freedom and rights with no distinction of personal characteristics, including religion. This is reflected on more recent human rights laws (e.g., Equality Act 2010), which have a direct impact on service delivery (regardless of the disciplinary area), healthcare generally and end of life care specifically. 


\section{Religious literacy}

Drawing on Malinowski's work (1954/2015), each society is subjected to two domains: the sacred and the profane. Religious literacy is almost a dialogue between the two, in contemporary practice.

According to Dinham and Francis (2015), religious literacy refers to the appropriate language and understanding to engage with religion and belief in policy and practice. Others have approached religious literacy differently (Prothero and Kerby, 2015; Moore, 2015; Ford and Highton, 2015). However, this paper considers the initial descriptor by Dinham and Francis (2015), while it takes into consideration the concept of cultural humility (Hook et al., 2013).

Religious literacy is described as the knowledge and understanding of religion and belief, as well as skills and abilities to appropriately engage with it. Cultural humility, on the other hand, explores the intrapersonal and interpersonal dimensions of the professional. In other words, 'an accurate view of self' and maintaining 'an interpersonal stance that is other-oriented rather than self-focused, characterized by respect for the others and a lack of superiority', respectively (Hook et al., 2013, p.2). Therefore, considering the interpersonal dimension of professionals complements the attempt toward appropriate and person-specific responses to religion, belief and spirituality.

The identification of the need to be literate in this area stems from the changing religious landscape across Europe, and Britain, since the post war years, and, therefore, largely from the migration waves in Britain after the end of World War II (Weller, 2007). This cross-national movement of populations at the time resulted in a diverse and multi-faceted contemporary environment: both multi-cultural and multi-faith in nature (ibid.).

The response to the diversification of the population, however, was not immediate either in policy and practice, or in every-day life. Drawing from the critical race theory (Delgado and Stefancic, 2012) when referring to multi-racial societies, norms, attitudes and behaviors 
gradually took hold in favor of the mixed population. Similarly, religion and belief have long not been in the centre of the conversation: at least not publicly (Davie, 2013).

Dinham (2015) explores how the changing religious landscape in the UK is playing out in contemporary society: in politics, policy and professional practice. Dinham (2015) suggests that the church has always been a contributor of welfare services and social care in the community. Not always recognized in that role, nonetheless, the church sometimes has an 'invisible presence' (ibid., p.106). Considering that, religion has always remained a strong part of people's lives, however publicly disengaged with it they may appear to be; people (i.e., different agents in different public spheres) have not necessarily developed appropriate literacy to publicly address religion and belief, and when they are asked to do so, they may lack the language and skills.

In summary, since the post war-years religion and belief had a covert identity in their role in society and their contribution in social welfare. When religion was once again identified as an important aspect of life (Berger, 1999) policy makers, politicians and professionals were faced with a challenging situation. Having not addressed these matters for over fifty years, amounted to lack of religious literacy (Dinham and Francis, 2015).

\section{Microaggressions}

Research suggests that it is almost impossible not to inherit biases and stereotypical attitudes from our ancestors (Sue and Sue, 2008; Sue, 2003; Baker and Fishbein, 1998; Banaji and Greenwald, 1995; Fiske and Stevens, 1993). According to Nelson (2006) and Sue (2003), such prejudices or stereotypical behaviors may exist in the conscious or unconscious level, or on the borderline. The realization of prejudice and discriminatory behavior is essential in the process of tackling it (Sue, 2010). However, when these behaviors are embedded in the unconscious, people 'are likely to unintentionally behave in subtle discriminatory patterns.' (ibid., p.22). 
Linking this to the multi-cultural and multi-faith society of today, research shows that people can address overt discrimination easier than they can deal with subtle and unintentional forms of prejudice or stereotypes when treated by others (Salvatore and Shelton, 2007; Sue, 2003). 'It is the unconscious and unintentional forms of bias that create the overwhelming problems...in our society.' (Sue, 2010, p.23).

Microaggressions is a term coined by Pearce (Sue 2003) but popularized largely by Sue et al. (2007) and Sue (2003). Sue et al. (2007, abstract) suggest that:

Racial microaggressions are brief and commonplace daily verbal, behavioral, or environmental indignities, whether intentional or unintentional, that communicate hostile, derogatory, or negative racial slights and insults toward people of color. Perpetrators of microaggressions are often unaware that they engage in such communications when they interact with racial/ethnic minorities.

The term has been used to address such behaviors in relation to race, gender and sexual orientation at large (Sue, 2010). Further exploration in research relates to religion and the 9/11 events in the USA. This has led to religious microaggressions at the expense of the Muslim communities (Delgado and Stefancic, 2012; Sue, 2003). However, this paper is not concerned with religious microaggressions. It is rather an encounter with how lack of religious literacy may indicate unintentional and unconscious forms of microaggression.

Sue et al. (2007) propose a taxonomy of microaggressions. All forms fall under three main categories: microassaults, microinsults and microinvalidations. These three categories differ in terms of intentionality and consciousness of the perpetrators. Sue (2010, p.28) explicitly describes each category: 'microassaults are conscious, deliberate, and either subtle or explicit...biased attitudes, beliefs, or behaviors that are communicated...through environmental cues, verbalizations, or behaviors.' Microinsults are also often conscious, but these are 'communications that convey rudeness and insensitivity' (Sue, 2010, p.29). The last 
category is microinvalidations. These are often unconscious, and refer to communications that 'exclude, negate, or nullify the psychological thoughts, feelings, or experiential reality of a person.' (ibid., p.29).

This paper focuses on microinvalidations and how lack of religious literacy may lead to unintentional and unconscious behaviors that diminish or eliminate the importance of the role of religion in the experiences of service users. Drawing from Ikemoto's (2013) suggestions on racial hierarchy, this paper also considers religious hierarchy (Christian-centered approaches) and how that plays out in service delivery in EOL care, and in relation to signs of microinvalidation.

\section{Method}

This paper is the result of a qualitative, ethnographic study undertaken from August 2013 to August 2014. This study employed participant observation as its main method. Participant observation may involve active participation or pure observation (Marshall and Rossman, 1999). Observation is an overt process that entails pure note-taking and recording of events and artefacts in the environment where the study is taking place. Coupled with the aim of this study (i.e., to record professionals' responses to religious and spiritual indicators of service users', but without active participation in the care of the latter) observation was deemed the most appropriate method. So the researcher assumed the role of participant observer (Bernard, 2013), which involved some interaction with the participants, predominantly to do with informal discussions about observed behaviors and attitudes. These discussions took place in a debrief meeting at the end of each day.

The method was complemented with unstructured and brief qualitative interviews (Bryman, 2016) with the participants. During these interviews, the participants were presented with the findings from participant observation and were asked to commend them. 


\section{Participants}

Twelve participants took part in the study. Eight (8) were women and four (4) were men. All participants were Health Care Professions Council (HCPC) registered and practicing in hospice care. The HCPC is the regulatory body of 16 professions, including Social Work in England. Thus, the term 'healthcare professionals' is used to refer to all participants in this study. Eight (6) were nurses, two (2) social workers, two (2) doctors, one (1) occupational therapist, and one (1) was physiotherapist. All participants were observed throughout the course of 12 calendar months and on a weekly basis. Additionally, three of the research participants have practiced in hospice care from 0-3 years, two have 4-10 years of experience, and the rest (7) are professionals with over ten years' experience in the field. The names that have been used in this paper are pseudonyms considering confidentiality and privacy of identity.

Measures

Religious literacy. Participants were asked to identify their knowledge and understanding of religion and belief based on the question: "What knowledge do you acquire about various religious beliefs and what is your understanding of how such beliefs influence the service user experience?'

\section{Process}

After the research proposal was approved by the NHS ethics research committee and the author's departmental ethics committee, a call for research participants went out to all employees of two hospices in London, UK. The call for participants briefly explained the research project, its aims and purpose. It also described how participant observation would be undertaken, and contact details were given for interested employees to get in touch with the researcher. Also, information was made available in the call which invited potential participants to partake in an interview at the end of the participant observation, during which the findings would be presented to them. 
Nineteen (19) employees contacted the researcher after the call, however only twelve took part in the study, due to ethical concerns raised by the rest during the first meeting. These concerns related to the presence of a researcher when interacting with service users; professionals with such concerns were primarily those unfamiliar with the research methodology used in this study. In the first meeting, all relevant information was given to the research participants, ethical issues were discussed and an informed consent form was signed off.

Participant observation took the form of naturalist observation (Bryman, 2016), which allowed for the researcher to closely observe how professionals responded or not to religion, belief and spirituality related issues during professional encounters with patients in hospice care. In addition, with participant observation the data are gathered at the time of its occurrence, as well the researcher having the privilege to gain first-hand knowledge (Silverman, 2011; Bryman, 2016). Furthermore with participant observation, the researcher had the chance to gain insight based on non-verbal and environmental evidence as well.

Further, the unstructured in-depth interviews allowed for the findings to be confirmed and increased their validity (Bryman, 2016). The interviews remained unstructured to allow the participants to tailor the conversation based on their response to the findings from participant observation.

Ethical approval for the study was obtained from the Ethics Approval Committee of the author's home institution during the study, as well as the NHS Ethics Committee.

\section{Findings and Discussion}

Drawing from Sue's model (2010), findings from this study illustrate indications of microinvalidation only and not at all microinsults and/or microassaults. Three major categories emerged: non-verbal, verbal and environmental indications. The following subheadings are 
discussing each category separately, while the findings are illustrated via selected vignettes that have been extracted from the ethnographic notes.

\section{Non-verbal indications}

Healthcare professionals have demonstrated unconscious non-verbal actions that appeared to either exclude, or nullify the feelings of the service user in that moment. In those situations, professionals showed goodwill and empathetically engaged with service users. Observations, however, indicated signs of microinvalidation. For example, professionals might oversee the religious or spiritual significance associated with certain objects or rituals that service users perform (e.g., breathing exercises). This may jeopardize the lived experiences of the service users and marginalize personal stances towards death, dying and bereavement that relate to religion and belief (Kagawa-Singer and Backhall, 2001).

\section{Vignette 1}

It is 12:45am when I returned from my break to the ward on the second floor. I was observing Matilda, a staff nurse, during her night shift. I had already been observing her for three hours, and it had been a rather quiet evening. Matilda invited me to follow her to a patient's room where the buzzer light went off. When arriving in the room we found the service user laying half off the bed, trying to pull himself back up from the hoist handle above him. Matilda attended to his assistance straight away, and shortly after the service user was back in the bed and calmer than before. Matilda looked at me and made a sigh of annoyance. She then returned to her business of tucking the service user in his bed. In doing so she found a rosary in the service user's hands, which she took and placed in a drawer next to the bed. The service user attempted to regain possession of the rosary, reaching to the drawer, but Matilda placed his arm back under the covers, tucked him in and shook her head in dismay.

There are many aspects of this narrative. We see a caring nurse, who is committed to her work and demonstrates professionalism, as she attends to the assistance of the service user when 
needed and shows empathy while tenderly tucking the service user back in bed and into a comfortable position to go back to sleep. The vignette also shows a tired professional. The sigh of irritation and annoyance shows that the nurse had somewhat disapproved of the service user's action. It showed annoyance in connection to having had to attend to the patient's room and provide support.

This vignette depicts signs of religious microinvalidation, or perhaps microinvalidation with a religious element. The nurse provided care for the service user, but did not engage in the event in terms of exploring the reasons behind the person being partially displaced on the bed; the rosary in his hands, and did not notice the devastated facial expression when it was gone, tidied away into the drawer and out of reach. Following an informal chat with the service user, it became evident that he deliberately reached for the rosary in the drawer, in the middle of the night, got a hold of it, and upon then found he could not reposition himself properly on his bed. This service user was experiencing strong feelings of attachment with his faith, or with a higher power as he has found himself vulnerable, in a hospice bed, terminally ill from cancer staged 4 and deteriorating fast, and with limited visits received in the three weeks during which he has been admitted. This incident may be informed by Richards and Bergin's (2005) suggestion of a spiritual strategy, it is the moments that the service user feels most vulnerable that professional practice should be the most understanding, competent and supportive, and, in the author's own argument (2015) religious literate.

\section{Vignette 2}

It is very early on a Saturday morning and the ward nurse is going in to administer medication to the patients. We are entering a four-bed room, where three ladies are inpatients. While the nurse is preparing doses of medication for the different patients, I am gazing in the room and gathering information that would inform my study. At the far-right side of the room there is a lady who can hardly lift up her head and look at us, so she is making small chat with the nurse. 
Next to her, on the nightstand, there are three religious icons and a medium size cross. Also, two rosaries are laid on the nightstand, right next to the holy water, as the little made-up sign on the bottle indicated. All were placed in an orthodox manner and with particular attention. The nurse approached the lady's bed with a tray full of meds. She needed room to lay the tray and complete her task that morning. She puts the icons on top of each other, places the rosaries on top and places them on the bed. She then places the holy water in the back of the nightstand, probably out of reach from the service user. When the medications had been administered the nurse placed the pile of items back on the nightstand without placing them in their original position.

Once again, this is a professional who, in this situation, has demonstrated excellent practice skills; she engaged with the patients throughout the whole time we spent in the room, she made jokes, showed empathy, communicated with the service users. Nonetheless, unintentionally, and unconsciously she had shown signs of microaggression.

Even though the nurse was completing an essential task (i.e., pain control) for the benefit of the patient, she, concurrently, showed signs of disrespect toward the patient's religious (or spiritual) needs. The action in this vignette shows an act of devaluing someone's lived belief and how that links to the psychological experience of death and dying. In other words, this may be viewed through the lens of cultural humility and the importance of showing respect toward the other (Hook et al., 2013). However, people may not always be aware when they lack respect for the other (Goffman, 1978).

Non-verbal indications of microinvalidation took other, more subtle forms as well. An example is illustrated in vignette 3 , when observing a session between a social worker and a patient's family member.

\section{Vignette 3}


It is late in the afternoon. I have spent a five-hour shift with Diana, a hospice social worker, who has kindly agreed to talk to me about her practice in the hospice and allow me to ask so many questions. Little before $4 \mathrm{pm}$, Diana receives a phone call from the respite ward to find out that a family member, John, of one of her service users has been highly distressed due to recent medical news. We made our way to the ward and without any delays met with John in the quiet room at the end of the ward's corridor. When entering the room, John touched on a Bible sitting on a small table in the middle of the room and crossed his chest. Before the latter action was complete, Diana was already putting away the Bible, along with other objects on the table, to clear the space and have a more focused discussion with John.

Weingarten (1998) explored extensively how small gestures, words and actions can influence the experience of a patient or client, but also the relationship between the latter and the professional. In line with cultural humility and the building up of a trusting relationship (Tervalon and Murray-García, 1998), such a small action by the social worker (i.e., putting away the Bible while John is crossing his chest) may hinder the professional relationship between the two, while it may lead to misunderstandings of religious bias. In this vignette, the social worker did not intend to either invalidate or nullify in any way the service user's experience. Nonetheless, the social worker's action interrupted a spiritual moment that John had, which appeared to directly link with his distress about his family member's condition.

\section{Verbal indications}

Similar signs of microinvalidation were evident here, in verbal interaction. Verbal indications were unconscious, with an unconscious meaning (Sue et al., 2007). In other words, professionals appeared unaware of the outcomes of their actions as those related to microinvalidations. Findings that feed into this category were drawn either from long conversations between a healthcare professional and the patient, or from informal 
conversations that took place either in a patient's room, the corridor, or at the nurse station in the ward, between the researcher and professionals.

Table 1 shows the most common examples of verbal indications of religious microinvalidation. The table lists exemplar microinvalidations, which may or may not communicate the same message. Regardless, all these examples are pure from intentional harm, while healthcare professionals, during this research project, have always demonstrated the best of intentions and acted to the benefit of service users.

$<$ Table 1 somewhere here $>$

The examples depicted in table 1, if taken out of context, may appear patronizing and sometimes rude. This is not what the findings here show. Sue et al. (2007) explored racial microaggressions in a holistic way. The authors explored verbal microaggressions as well as their unconscious meanings. The latter is developed by the person verbally indicating microaggression, based on the victim's subjectivity. Healthcare professionals here appear to address religious related issues in various ways. Along with each single statement in table 1 is also a construction of the circumstances under which it was said and the parties that were involved.

\section{Vignette 4}

It is late in the afternoon and I am still observing a social worker who is due to meet with a patient, Mark, in their room. The social worker had worked with that patient for over two months and is planning to check in with them. We entered the room and things were very quiet - only one more patient in the room, who was asleep. The social worker moved a chair next to the bed and started talking with Mark, while I sat in a chair placed at the far end of the bed. More than fifteen minutes in the conversation, Mark started talking about his faith and linked it with his experience of being ill. He referred to his faith as a place where he can retreat when 
he does not want to think of his illness anymore. The social worker then asked Mark: 'Does that make you feel better'?

It is suggested that healthcare practice is filtered via a Christian-centered lens (Pentaris, 2013), and this is apparent in some of the verbal indications of microinvalidation (Table 1). In other words, when responding to needs related to religion, belief and spirituality, it is done via a Christian-centered lens. This practiced framework occasionally may act as an indicator of invalidating other than Christian religious identities (e.g., 'you would be a very good Christian.'). Surely, there are pure intentions in this statement, and the professional who makes such statements may only suggest that the service user has all the good qualities and is guided by values and principles that may be found in Christian religious teachings. Nevertheless, the unconscious message may be understood in terms of giving permission to someone to think that they are even better than they already are, and that Christian belief is higher in the hierarchy of belief systems (Ikemoto, 2013, for racial/religious hierarchy).

This framework leads to the second emerging theme in this category: ambivalence. Comments like 'there is only one god' and 'the Quran is equivalent to the Bible' are indicators of a twofold message. Initially, healthcare professionals seem to be ambivalent towards difference. Findings show that professionals find it difficult to comply with the diverse and multifaceted environment in which practice takes place (also implied in Melnyk and Fineout-Overholt, 2011). This is evident by the lack of engagement in in-depth conversations about different faiths, while anything outside of Christian-minded culture is perceived through the latter (Author's own, 2015).

The second stream of this message takes us to a place where professionals, unconsciously and unintentionally, employ a method that undermines experiential feelings of belief and faith, when this is regarded outside of Christian belief. 
Last, and following on from undermining belief, findings showed that oftentimes comments or questions to service users demonstrate disbelief. This is concerned with acceptance of the role that religion, belief, and spirituality have towards the end of life of service users' (Canda and Furman, 2010). Parkes et al. $(2015 ; 1997)$ explore dying and bereavement across different religions, and they conclude that the experiences of death and dying are unique and original, bound to the person's cultural and religious background. Dismissal or unconscious avoidance of one's own belief from these experiences may jeopardize their quality and the quality of care generally.

\section{Environmental indications}

Numerous changes in the healthcare system bring up challenges to Hospice Care as well. Death and health policies are crowded with oftentimes compatible or contradictory concepts and perceptions (Pentaris, 2015; Foster and Woodthorpe, 2016). Professional practice is however directly informed and influenced by current policies and legislations. That said, it is in light of equality and diversity guidelines and procedures that hospice care has confined itself in an ongoing secularizing process, all due to lack of religious literacy; appropriate language to address religion, belief, and spirituality identities of service users (Author's own, 2015).

\section{Vignette 5}

When I enter the ward on the second floor, I take out my notebook and start jotting down notes as I walk along the corridor and observe the space. It is surprising to me that initially I do not see any religious representation whatsoever. A little later, and after I have sat down making notes for a while, I spot an icon, a religious icon, right next to the TV in the common area. Following that, I was pointed to a crucifix hanging on the wall of the physiotherapy room. These were the only objects, according to my observations, present in the ward.

This is an extract from my notes during participant observations. The icon was of Virgin Mary with Jesus Christ in her arms. This is an additional proof that end of life care is framed via a 
Christian lens, despite its secular character. It almost seems that hospice care retains its Christian history and foundations, while secular approaches are employed in order to become more inclusive and appropriate to all in society.

Indeed, end of life care is inclusive. Nonetheless, full of reminders of the predominant belief system that acts as an overall arc of care, as well as signs of microinvalidation of other than Christian faiths. If the claim that hospice organizations are multi-faith and that their practice is informed by all faiths and none, should there not be Buddhist mala beads, a Muslim Tuareg cross, a representation of Faravahar, and so on next to the crucifix in the abovementioned extract?

People of other than Christian faiths, in this instance, may experience feelings of nonacceptance or feelings of being inferior or disapproved by others. Such feelings of nonacceptance and consecutively not belonging may lead to disengagement from the relationship between professionals and service users, and compromise the service user's experience while in hospice care. Drawing on cultural humility, it is the concept of lack of superiority that can add to explaining this issue. According to Hook et al. (2013), respect and lack of superiority toward the other may impact on the service user experience much more effectively than the concept of cultural competence. Lack of superiority, though, may not only be evident through one's actions and words, but also through the environment in which the service user is cared for. In vignette 5, the researcher has noted two representations of the dominant religion, but none from others. Perhaps this is a sign of unintentional show of superiority and dominance, which deems further examination and exhaustive exploration.

\section{Religious Microinvalidations in EOL care and Social Work}

The findings presented in this paper refer to professionals registered with HCPC in the UK, inclusive of social workers. Despite the mix of professions in the analysis of the findings, this 
section will focus on and draw conclusions related to social workers in their effort to practice in an anti-oppressive, anti-discriminatory manner.

Religion and belief play an important role in service users' lives, and therefore these should be considered in social work assessment, intervention, evaluation and policy planning (Moss, 2005; Holloway and Moss, 2010). Thompson's (2012) account in connection to the significance that religion and belief have in people's lives is no different:

Religious beliefs are a fundamental part of many people's identity and can therefore be a major guide to action on the basis of moral principles or required practices (for example, rituals). For a high proportion of people their sense of who they are and how they fit into the wider world is largely a matter of their religion. Their religion colors all aspects of their lives and their relationships with other people and wider society (p.168).

The social work profession is shaped by the principles of sensitive and ethical practice, as well as is informed by the increasing diversity in society. Social workers are obliged to an ethical professional behavior towards their service users (Shardlow, 2002). Similar to what Dominelli (1993) highlights, social work practice shall be open and non-judgmental to differences, no matter whether the profession is familiar with those differences yet or not.

Belief and non-belief are inherently linked with the experiences of death, dying and bereavement (Corr and Corr, 2012), and consequently with end of life care, too. Lack of acknowledgement of or lack of ability to acknowledge the significance of religion and belief suggests lack of understanding and empathy in the area by professionals. Walter (1999) suggests in his account about grief that if healthcare professionals were well equipped to provide spiritual care, then this ought to happen. Author's own (2015) concludes that social workers in hospice care are the professionals who have provided the most psychosocial support to patients and their families and friends. Spiritual care falls under the umbrella of psychosocial 
care (Author's own, 2015; Canda and Furman, 2010), and therefore it is expected that social workers have acquired the level of professionalism, which shows few signs of microaggression. This is of course true, but necessarily with limitations.

Religious microinvalidations, as shown in the findings above, illustrate the high risks of unconscious misconduct when it comes to religious sensitive practice (Thompson, 2012; Canda and Furman, 2010), and religious literacy (Dinham and Francis, 2015). According to Dinham (2015), religion had not been publicly identified as an active medium of society's functions for a long time, and next time that society decided to talk about it, people had lost their ability to do so. This paper is developed along the trajectory of this argument.

Lack of religious literacy in EOL care (Author's own, 2015) may impact on service users, professionals, the organizational context and the relationships among all. A large part of this impact is concerned with religious microinvalidations and social work is highly concerned with providing care that best meets the needs of service users and functions to their benefit, regardless, but also in terms of their religious identification or practices, i.e., with religious literacy. Furthermore, the social work profession is concerned with advocacy and promoting human rights and well-being. It is these values that place the profession of social work in the center of this argument. The responsibility for continuous professional development and growth is also inclusive of the ongoing responsibility of being aware of the changing circumstances that may shape social work organizational operation (Hughes and Wearing, 2013).

\section{Conclusions}

It is surprising and unforeseen, in an EOL care system that embraces diversity and equal opportunity, adopts an inclusive and non-judgmental character, as well is interested in the increase of the quality of life (DH, 2011; Cassel and Field, 1997); to come across these findings. 
This conclusion should be read with caution, however. While the findings present current practice as it relates to how HCPs respond to religion, belief and spiritual needs of service users, the paper has not considered the political and economic context in which professionals practice. High organisational demands, financial implications on organisations, institutions and services, all impact on the resources available to practice. The findings from this study, thus, should be further explored with this context in mind.

HCPs seem to lack religious literacy in response to religion, belief and spiritual identities of the service users (Author's own, 2015). Secondly, that the way issues related to religion are addressed may indicate subtle signs of microaggression in professional practice.

This study has shown that few depictions from everyday practice may shed some light on issues such as microinvalidations occurring in practice. These are signs of microaggression, which may be easily missed, especially in a social work context that is crowded by legal framework assessments and procedural practice.

Religious literacy is paramount in order to overcome such challenges and better equip professionals when they are engaging with service users. Social workers often employ the role of an advocate, a liaison, or a mediator. In these roles, full understanding and comprehension of service user's identity plays a critical part; how can a social worker better voice the service user's rights, if they have not met the service user where they are at and understood the service user's world view to some extent.

The conclusions are neither comprehensive nor exhaustive, but a selection of a few concluding thoughts, according to the findings reported on in this paper. These thoughts include the significance of religion and belief as that relates to social work (Gilligan and Furness, 2006; Holloway and Moss, 2010), religion and belief in EOL care (Daaleman and VandeCreek, 2000; Author's own, 2015), and religious literacy (Dinham and Francis, 2015) as it relates to the above. 
Lack of religious literacy is not merely lacking the ability to talk about religion and belief. Lack of religious literacy in EOL care influences professionalism, while it indicates the high risk of religious microinvalidation.

\section{Limitations of the study}

Although the present study has been carefully prepared, there are certain constraints and shortcomings of which the researcher is aware. First, participant observation took place only in two hospices from the Greater London area. Drawing on the Person-in-Environment (PIE) theory (Karls and Wandrei, 1994) and the method itself (i.e., participant observation) (Bryman, 2016), participant observation results in data that are collected from behaviors within context and interactions between participants and their environment. The current study is limited to two settings, which narrows the options of transferability of the findings. Further, this study could be complemented from action research methods; seeking confirmation and commentary of the findings from the participants. Such an approach would enlarge the reliability of the study, yet would minimize its replicability. Lastly, the author is aware of the indirect link of the findings of this study with social work when considered from a wider perspective. The HCPC, which regulates the social work profession in England, is targeting health professions altogether. Therefore, the implications of this study refer to all professions under this category. Nevertheless, as the findings from this study have been approached from a social work perspective, the author highlights future trends for social work.

\section{References}

Ardelt, M. (2003), “Effects of religion and purpose in life on elders' subjective well-being and attitudes toward death", Journal of Religious Gerontology, Vol. 14 No. 4, pp. 55-77. Author's own. (2015). 
Baker, J.G. and Fishbein, H.D. (1998), "The development of prejudice towards gays and lesbians by adolescents", Journal of homosexuality, Vol. 36 No. 1, pp. 89-100.

Banaji, M.R. and Greenwald, A.G. (1995), "Implicit gender stereotyping in judgments of fame”, Journal of personality and social psychology, Vol. 68 No. 2, p. 181.

Becker, E. (1963), The denial of death, Simon \& Schuster, New York, NY.

Berger, P.L. (1999) “The Desecularization of the world: A global overview”, in Berger P. (Ed.), The desecularization of the world: Resurgent religion and world politics, William B. Eerdmans, Grand Rapids, MI, pp. 1-18.

Bernard, R. (2013), Social research methods: qualitative and quantitative approaches, Sage, London, England.

Bryman, A. (2016), Social Research Methods (5 $5^{\text {th }}$ ed.), Oxford University Press, New York, NY.

Canda, E.R. and Furman, L.D. (2010), Spiritual diversity in social work practice: the heart of helping, Oxford University Press, New York, NY.

Cassel, C.K. and Field, M.J. (Eds.) (1997), Approaching death: improving care at the end of life, National Academies Press, Washington, DC.

Corr, C. and Corr, D. (2012), Death \& dying, life \& living, Nelson Education, Belmont, CA. Daaleman, T.P. and VandeCreek, L. (2000), "Placing religion and spirituality in end-of-life care”, JAMA, Vol. 284 No. 19, pp. 2514-2517.

Davie, G. (2013), The sociology of religion: A critical agenda, Sage, London, UK.

Dinham, A. and Francis, M. (2015), Religious literacy in policy and practice, Policy Press, Bristol.

Dinham, A. (2015), "Religious literacy and welfare", in Dinham A. and Francis, M. (Eds.), Religious literacy in policy and practice, Policy Press, Bristol, pp. 101-111 
Department of Health (2011), Spiritual Care at the End of Life: a systematic review of the literature, Department of Health, England.

Dominelli, L. (1993), Social work: mirror of society and its conscience? Department of Sociological Studies, Sheffield.

Fiske, S.T. and Stevens, L.E. (1993), "What's so special about sex? Gender stereotyping and discrimination", in Oskamp S. and Costanzo, M. (Eds.), Gender issues in contemporary society, Sage, Thousand Oaks, CA, pp. 173-196.

Ford, D and Higton, M. (2015), "Religious literacy in the context of Theology and Religious Studies", in Dinham A. and Francis, M. (Eds.), Religious literacy in policy and practice, Policy Press, Bristol, pp. 39-54.

Foster, L. and Woodthorpe, K. (Eds.) (2016), Death and Social Policy in Challenging Times. Springer, London.

Freeman, M. (2017), Human rights. John Wiley \& Sons, London.

Gilligan, P. and Furness, S. (2006), "The role of religion and spirituality in social work practice: Views and experiences of social workers and students", British Journal of Social Work, Vol. 36 No. 4, pp. 617-637.

Goffman, E. (1959), The presentation of self in everyday life, Doubleday, New York, NY.

Goldsworthy, K.K. (2005), "Grief and loss theory in social work practice: All changes involve loss, just as all losses require change", Australian Social Work, Vol. 58 No. 2, pp. 167-178. Hart, B., Sainsbury, P. and Short, S. (1998), "Whose dying? A sociological critique of the 'good death"', Mortality, Vol. 3 No. 1, pp. 65-77.

Holloway, M. and Moss, B. (2010), Spirituality and social work, Palgrave Macmillan, London, England. 
Hook, J.N., Davis, D.E., Owen, J., Worthington Jr., E.L. and Utsey, S.O. (2013), “Cultural humility: measuring openness to culturally diverse clients", Journal of Counseling Psychology. Doi: $10.1037 / \mathrm{a} 0032595$

Hughes, M. and Wearing, M. (2013), Organisations and management in social work, Sage, London, England.

Ikemoto, L.C. (2013), "BioPrivilege”, Washington University Journal of Law and Policy, Vol. 42, pp. $61-81$.

Kagawa-Singer, M. and Blackhall, L.J. (2001), "Negotiating cross-cultural issues at the end of life: You got to go where he lives”, JAMA, Vol. 286 No. 23, pp. 2993-3001.

Karls, J.M. and Wandrei, K.E. (1994), PIE manual. Person-In-Environment System, National Association of Social Workers, Washington, DC.

Kaufmann, W. (1976), Existentialism, religion and death, New American Library, New York, NY.

Kellehear, A. (2017), "Current social trends and challenges for the dying person", in Jakoby, N. and Thönnes, M. (Eds.), Zur Soziologie des Sterbens, Springer Fachmedien Wiesbaden, Wiesbaden, pp. 11-27.

Kim, H.H. (2008), Impact of spirituality and religion on attitudes toward death and dying among Korean seniors living in Chicago, ProQuest, Ann Arbor, MI.

Kübler-Ross, E. (1969), On death and dying, Collier Books, New York, NY.

Kuczewski, M.G. (2007), "Talking about spirituality in the clinical setting: Can being professional require being personal?", The American Journal of Bioethics, Vol. 7 No. 7, pp. 411.

Malinowski, B. (1954/2015), Magic, science and religion, Martino Publishing, Mansfield Center, CT. 
Marshall, C. and Rossman, G.B. (1999), Designing qualitative research, Sage, London, England.

Melnyk, B.M. and Fineout-Overholt, E. (Eds.) (2011), Evidence-based practice in nursing \& healthcare: A guide to best practice, Lippincott Williams \& Wilkins, Philadelphia, PA.

Moore, D.L. (2015), “Diminishing Religious Literacy: methodological assumptions and analytical frameworks for promoting the public understanding of religion", in Dinham, A. and Francis, M. (Eds.), Religious literacy in policy and practice, Policy Press, Bristol, pp. 27-38.

Moss, B. (2005), Religion and spirituality, Russell House Publishing, Lyme Regis.

Nelson, T.D. (2006), The psychology of prejudice, Pearson, Boston, MA.

Parkes, C.M., Laungani, P. and Young, B. (2015), Death and bereavement across cultures, Routledge, New York, NY.

Parkes, C.M., Laungani, P. and Young, B. (1997), Death and bereavement across cultures, Routledge, London, England.

Pentaris, P. (2015), "Redefining religion and belief in end of life policies", in the proceedings of the Centre for Death and Society 2015 Conference at the University of Bath, England, 2015. Pentaris, P. (2013), "Health Care Practitioners and Dying Patients", Journal of Education, Culture and Society, Vol. 4 No. 1, pp. 38-44.

Prothero, S. and Kerby, L.R. (2015), "The irony of religious illiteracy in the USA”, in Dinham, A. and Francis, M. (Eds.), Religious literacy in policy and practice, Policy Press, Bristol, pp. $55-75$.

Richards, P.S. and Bergin, A.E. (2005), A spiritual strategy for counselling and psychotherapy, American Psychological Association.

Salvatore, J. and Shelton, J.N. (2007), "Cognitive costs of exposure to racial prejudice", Psychological Science, Vol. 18 No. 9, pp. 810-815. 
Saunders, D.C. (2005), Cicely Saunders - Founder of the Hospice Movement: Selected Letters 1959-1999, Oxford University Press, New York, NY.

Shardlow, S.W. (2002), "Values, Ethics and Social Work", in Adams, R., Dominelli, L. and Payne, M. (Eds.), Social work: themes, issues and critical debates, Palgrave in association with the Open University, London, England, pp. 37-48.

Scheffler, S. and Kolodny, N. (2013), Death and the Afterlife, Oxford University Press, Oxford. Silverman, D. (2011), Interpreting Qualitative Data: A guide to the principles of qualitative research $\left(4^{\text {th }}\right.$ ed $)$, Sage, London, England.

Sue, D.W. and Sue, D. (2008), Counselling the culturally diverse: Theory and practice, John Wiley \& Sons, New Jersey, NJ.

Sue, D.W., Capodilupo, C.M., Torino, G.C., Bucceri, J.M., Holder, A., Nadal, K.L. and Esquilin, M. (2007), "Racial microaggressions in everyday life: implications for clinical practice", American psychologist, Vol. 62 No. 4, pp. 271-286.

Sue, D.W. (2010), Microaggressions in everyday life: Race, gender, and sexual orientation, John Wiley \& Sons, New Jersey, NJ.

Sue, D.W. (2003), Overcoming our racism: The journey to liberation, John Wiley \& Sons, New Jersey, NJ.

Taylor, P. M. (2005), Freedom of religion: UN and European human rights law and practice. Cambridge University Press, Cambridge.

Tervalon, M. and Murray-Garcia, J. (1998), “Cultural humility versus cultural competence: a critical distinction in defining physician training outcomes in multicultural education", Journal of health care for the poor and underserved, Vol. 9 No. 2, pp. 117-125. Thompson, N. (2012), Anti-discriminatory practice, Palgrave McMillan, London, England. Walter, T. (1999), On Bereavement: The culture of grief, Open University Press, Buckingham. Walter, T. (1994), The revival of death, Routledge, New York, NY. 
Weller, P. (Ed.) (2007), Religions in the UK: Directory 2007-2010, University of Derby Press, Derby.

Witte Jr, J. (1996), "Law, religion, and human rights", Columbia Human Rights Law Revview, Vol. 28 No. 1, pp. 1-32.

Wong, P.T. (2008), "Meaning management theory and death acceptance", in Tomer, A., Eliason, G.T. and Wong, P.T. (Eds.), Existential and spiritual issues in death attitudes, Lawrence Erlbaum Associates, London, England, pp.65-87.

Table 1: Verbal indications of microinvalidation in EOL care

\begin{tabular}{|c|c|}
\hline \multicolumn{2}{|r|}{ Verbal Microinvalidations } \\
\hline Themes & Examples \\
\hline $\begin{array}{l}\text { Christian } \\
\text { centered } \\
\text { framework }\end{array}$ & $\begin{array}{l}\text { Here [at the hospice] we are comfortable with any faith, not just } \\
\text { Christianity. } \\
\text { I might be Christian, but I have many people from other faiths in my social } \\
\text { circle. } \\
\text { I would care for you even if you were not Christian. } \\
\text { You would be a very good Christian. }\end{array}$ \\
\hline $\begin{array}{l}\text { Ambivalence } \\
\text { towards } \\
\text { difference }\end{array}$ & $\begin{array}{l}\text { There is only one God. } \\
\text { The Quran is equivalent to the Bible. } \\
\text { The Muslim cross is like our cross [Christian]. }\end{array}$ \\
\hline $\begin{array}{l}\text { Disbelief } \\
\text { undermining } \\
\text { lived belief }\end{array}$ & $\begin{array}{l}\text { If this makes you feel better, then it is not for me to say anything. } \\
\text { Does that make you feel better? } \\
\text { Why do you believe? } \\
\text { Can you pray less loudly? }\end{array}$ \\
\hline
\end{tabular}

